\title{
Modern comprehensive ideas about characteristics of the physiological state of stallions and improving the technology of their preparation for mating
}

\author{
Olga Fedosova ${ }^{1}$, Galina Glotova ${ }^{1 *}$, Galina Ulivanova $^{1}$, and Evgenia Chukhina ${ }^{1}$ \\ ${ }^{1}$ Ryazan State Agrotechnological University Named after P.A. Kostychev, 390044, Kostychev St., 1, \\ Ryazan, Russian Federation
}

\begin{abstract}
The paper presents the results of studies of the physiological state of stallions and their reproductive function in respect of the season, and according to blood samples the mechanisms of their physiological processes are adjusted using the ultrafine metal-polymer composition "iron-copper-zinc". According to such biochemical blood parameters of stallions as total protein and its fractions: lactate dehydrogenase (LDH), alkaline phosphatase (ALP) and $\alpha$-amylase, significant differences in the seasonal aspect were revealed. A number of features of blood morphology in connection with the season were noted. These were an increase in the concentration of erythrocytes, leucocytes, hemoglobin, eosinophils and lymphocytes in spring. An increase in the concentration of testosterone, the main populations of lymphocytes and subpopulations of $\mathrm{T}$ cells in the blood of stallions in the spring-summer period was established. The positive effect of the composition of nanosized metals on metabolic and enzymatic processes was revealed.
\end{abstract}

\section{Introduction}

Horse breeding was once one of the main directions in domestic animal husbandry. At present, due to decrease in the number of horses and uncertainty about the further reorganization of horse farms and stud farms, the activation of mating campaign is urgent, since the yield of foals remains quite low today, slightly exceeding $60 \%$. To increase this indicator, it is necessary to be able to adjust the reproduction process itself, directly preparing the animals for mating.

Recent developments in the field of physiology of horse breeding have led to intensification of biotechnological and neuroimmunoendocrine studies [1-4]. The use of nanotechnology, in particular, ultrafine metal polymer compositions, is of great interest, but their effect on the animal organism has not been fully studied [5-8].

\footnotetext{
*Corresponding author: galka270280@yandex.ru
} 
The purpose of the work is to identify the relationship between the physiological state of stallions and reproductive function in respect of the season, and according to the obtained blood tests to adjust the mechanisms of their physiological processes using the ultrafine metal-polymer composition "iron-copper-zinc".

\section{Materials and methods}

To achieve this purpose, seasonal studies of the morphological and biochemical blood composition of experimental animals were carried out. The physiological condition of stallions was also evaluated in mating campaign by the stages of application of the ultrafine metal-polymer composition "iron-copper-zinc" (UDC MPK-3K). The studies were carried out on three half-blood stallions (9-10 years old) in the All-Russian Research Institute of Horse Breeding (ARRIHB) and seven stallions of Russian horse breed (9-10 years old) in Starozhilovsky stud farm. For biochemical blood tests, an automatic biochemical analyzer "Sapphire 400" was used. The determination of blood cells was carried out using SysmexXT-2000i automatic hematology analyzer. Using immunological studies, the level of expression of markers of certain populations of lymphocytes and subpopulations of $\mathrm{T}$ cells was determined. Immunophenotypic characterization was performed by immunofluorescence with the help of FACScan instrument. The concentration of total testosterone in serum was carried out using immunochemical system Access.

For the study, the following dosage of UDC MPK-3K was used: $1.0 \mathrm{ml}$ of nanodispersion per $100 \mathrm{~kg}$ of live weight of the experimental animal (1.0 ml of MPK-3K contains $0.08 \mathrm{~g}$ of iron, $0.08 \mathrm{~g}$ of copper and $0.04 \mathrm{~g}$ of zinc) once (at the beginning of the experiment) and again after three weeks.

\section{Results and discussion}

The results of biochemical blood tests provide an opportunity to understand the physicalchemical processes taking place in the blood system completely and to control the physiological state of the animal.

The content of albumin in the blood serum of the stallions was quite stable (Fig. 1).

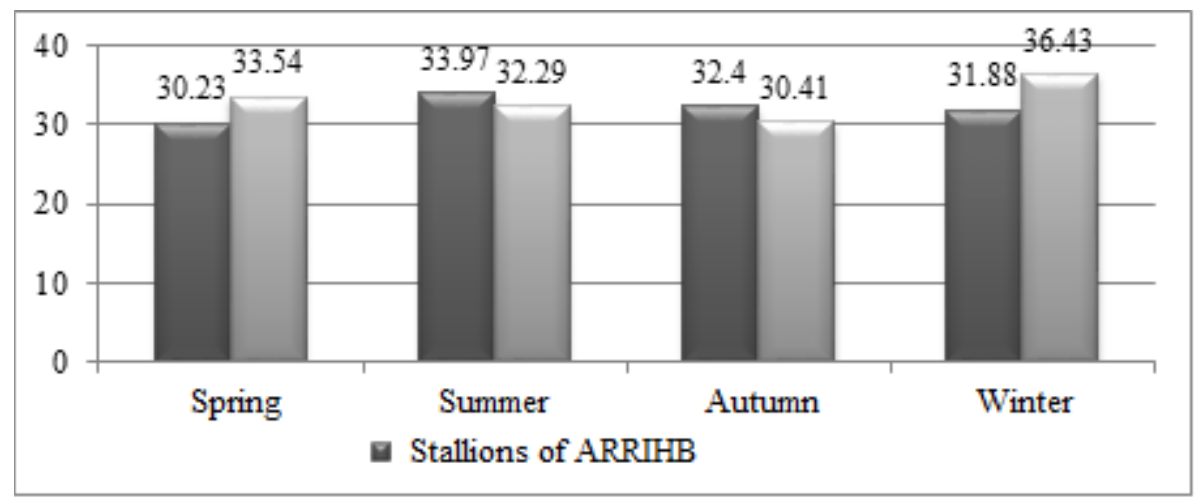

Fig. 1. The content of albumin in a seasonal aspect, $g / 1$

The level of globulins of the stallions of Starozhilovsky stud farm in spring was 35.31 $\mathrm{g} / \mathrm{l}$ and in the summer this indicator was slightly higher and amounted to $42.29 \mathrm{~g} / \mathrm{l}$, which can be associated with the transition of horses to green fodder. The highest level of 
globulins of animals of the All-Russian Research Institute of Horse Breeding occurred in spring and amounted to $46.93 \mathrm{~g} / \mathrm{l}$, which is associated with the activation of non-specific protection factors. Further, there was a downward trend in this indicator: summer - 39.9, autumn - 35.33 and winter - 33.46 g/l (Fig. 2).

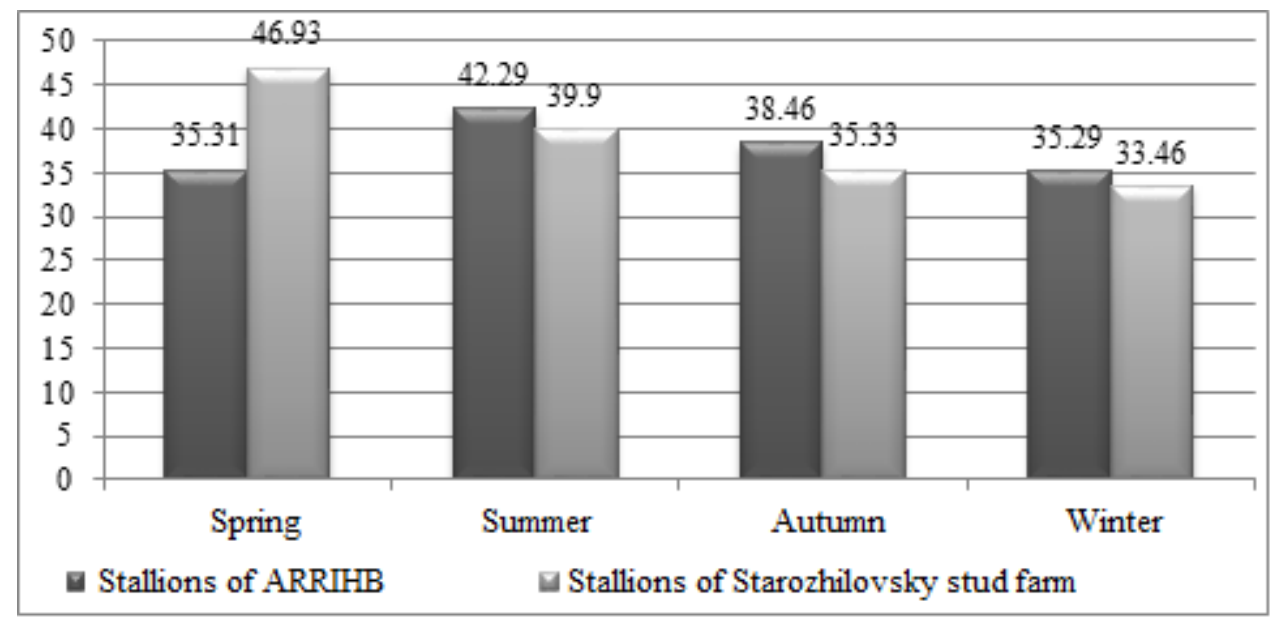

Fig. 2. The content of globulins in the seasonal aspect, g/l

It was found that the maximum activity of lactate dehydrogenase was recorded in stallions in the spring-summer season (stallions of the experimental stable $488.33 \pm 84.67 \mathrm{u} / \mathrm{l}$ (spring) and $468.67 \pm 41.39 \mathrm{u} / 1$ (summer), stallions of Starozhilovsky stud farm $455.57 \pm 47.72 \mathrm{u} / 1$ and $729.29 \pm 32.84 \mathrm{u} / \mathrm{l}$, respectively, whereas in the cold season (autumn, winter) the LDH activity of all the animals studied significantly decreased.

Analysis of the concentration of creatine phosphokinase showed no seasonal differences, but the greatest activity of the enzyme occurred in the autumn period - 243.4 $\mathrm{u} / \mathrm{l}$. The activity of other enzymes (alkaline phosphatase, $\gamma$-glutamyl transpeptidase, $\alpha$ amylase) was also higher in spring. A probable reason for this can be the increased reproductive activity of stallions in the mating period.

Assessment of the mineral composition of blood was carried out by the content of $\mathrm{Ca}, \mathrm{P}$, $\mathrm{K}, \mathrm{Na}, \mathrm{Fe}, \mathrm{Cu}, \mathrm{Zn}$. Their dynamics was very diverse. So, if the calcium content was quite constant and was at the level of $2.77-2.95 \mathrm{mmol} / \mathrm{L}$, then the content of such elements as phosphorus, potassium, sodium, iron and copper was characterized by seasonal dynamics. Moreover, in spring there was a peak in the content of phosphorus $(1.6 \mathrm{mmol} / \mathrm{L})$, potassium $(4.16 \mathrm{mmol} / \mathrm{L})$, iron $(25.39 \mathrm{mmol} / \mathrm{L})$. There was a peak in the content of sodium $(144.67$ $\mathrm{mmol} / \mathrm{L})$ in winter and that of copper $(23.67 \mathrm{mmol} / \mathrm{l})$ and zinc in autumn.

One of the research objectives was to evaluate the composition of blood cells. The results showed a clear seasonal trend. By the level of red blood cells, the maximum concentration occurred in the spring-summer season of the year. The stallions of the experimental stable had $8 \pm 0.58 \times 10^{12} / 1$ and $5.77 \pm 0.75 \times 10^{12} / 1$ and stallions of Starozhilovsky stud farm had $9.01 \pm 0.3 \times 10^{12} / 1$ and $7.26 \pm 0.35 \times 10^{12} / 1$. The dynamics of the level of hemoglobin in the blood was similar.

The total number of leukocytes in spring and summer was the largest one, which indicates the functional activity of protective reactions in animals during these seasons. The analysis of the leukogram showed a significant effect of seasons on its composition. There were fewer neutrophils in summer (stallions of the All-Russian Research Institute of Horse

Breeding - 49.33\% and animals of Starozhilovsky stud farm - 49.29 $\pm 2.78 \%$ ) compared with winter (stallions of the All-Russian Research Institute of Horse Breeding - $65.67 \%$ and 
stallions of Starozhilovsky stud farm - 70.2\%), which indicated the adaptation of the body to winter conditions.

The amount of eosinophils in the blood of animals in summer was 5.44-6.4\% higher than that in autumn. A possible reason for this may be a change in the technology of management.

The level of monocytes in the stud stallions did not have seasonal dynamics and amounted to $6.29-8.4 \%$. In summer and winter this indicator was quite high in stallions of the All-Russian Research Institute of Horse Breeding (7.67-9.33\%), but in autumn it decreased significantly $(2.67 \%)$.

The number of lymphocytes in the blood of stallions was the smallest in winter (25.33$20.2 \%$ ) and increased in spring (38-34.43\%), which indicated the activation of immune factors in experimental animals in a mating campaign. As a result of studies of immune parameters of blood of animals in the All-Russian Research Institute of Horse Breeding, it was found that in autumn and winter the activity of T-total lymphocytes $(37.0 \%$ and $27.33 \%)$, T-helpers $(18.33 \%$ and $12.67 \%)$ and T-suppressors $(20.67 \%$ and $12.33 \%)$ decreased. B-lymphocytes were stable and averaged $12.17 \%$. At the same time, the stallions of Starozhilovsky stud farm showed a maximum decrease in these indicators in winter: Ttotal lymphocytes $(31.3 \%)$, T-helpers (16.5\%), T-suppressors $(11.5 \%)$ and B-lymphocytes $(5.5 \%)$.

Analysis of the testosterone content in the blood serum of stallions showed that in autumn there was a general tendency to lower it. While before the mating campaign (February-March) the testosterone in the blood serum of the stallions of the All-Russian Research Institute of Horse Breeding was at the level of $0.43 \mathrm{ng} / \mathrm{ml}$ and $0.33 \mathrm{ng} / \mathrm{ml}$ during the mating season. For the stud animals the parameter was much higher: February - 0.37 $\mathrm{ng} / \mathrm{ml}$ and March - $1.26 \mathrm{ng} / \mathrm{ml}$. The androgen level in the animals varied due to seasonality, which indicated the need for further monitoring of this indicator for several years.

After a single use of UDC MPK-3K, the content of both the total protein and its fractions remained practically unchanged, which is important for maintaining the constancy of the internal environment of the body (Fig. 3).

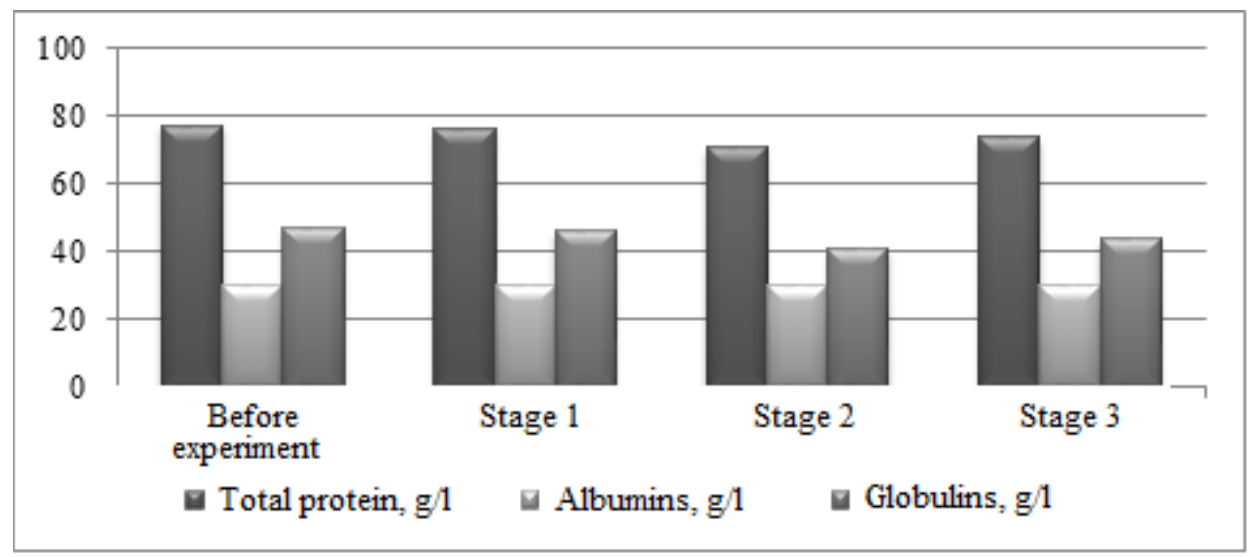

Fig. 3. The content of total protein and its fractions in the blood of stud horses under the action of UDC MPK-3K

Analysis of the LDH activity in the blood serum of experimental animals allowed to conclude that the activity of this indicator increased by the first stage of the experiment (488.33-582.67 $\mathrm{u} / 1)$. Perhaps this is due to the fact that zinc is a part of this enzyme. By the next stage, the enzyme also had a high value $(540.67 \mathrm{u} / 1)$ and by the end of the experiment the LDH activity decreased, amounting to $476 \mathrm{u} / 1$. 
The level of alkaline phosphatase involved in carbohydrate metabolism indicates energy processes in the body (at the beginning of the experiment this indicator was $372.33 \mathrm{u} / 1$ ), and at the second stage it was $428.33 \mathrm{u} / \mathrm{l}$. By the end of the experiment the enzyme activity decreased to $352.67 \mathrm{u} / \mathrm{l}$.

The activity of $\gamma$-glutamyl transpeptidase first increased from 13.77 to $15.2 \mathrm{u} / \mathrm{l}$ (stage 1 ) and then decreased to $10.87 \mathrm{u} / 1$.

Since the composition used contains such trace elements as copper, iron and zinc, their concentration in the blood serum of animals was studied. A lack of zinc in the body can cause an increased susceptibility to infectious diseases, impaired prostate function, infertility and hematopoiesis. So, the dynamics of the zinc content indicates an increased use of the trace element in metabolism. The iron content at the beginning of the experiment was $29.87 \mu \mathrm{mol} / 1$, a week later (after the first use of the nanocomposite) it was $41.47 \pm 5.28$ $\mu \mathrm{mol} / \mathrm{l}$ and then it decreased again $(22.4 \mu \mathrm{mol} / \mathrm{l})$. The repeated administration of the preparation contributed to an increase of up to $33.93 \mu \mathrm{mol} / \mathrm{l}$.

The first use of the preparation also led to a slight increase in copper from $14.5 \mu \mathrm{mol} / \mathrm{l}$ to $15.03 \mu \mathrm{mol} / 1$ at the beginning.

Analysis of the morphological parameters of blood showed that the red blood cell content after the first injection of the preparation increased from $8.0 \times 10^{12} / 1$ to $9.47 \times 10^{12} / 1$ and then, while maintaining the trend, hemoglobin also increased from $133.33 \mathrm{~g} / 1$ to 140.67 $\mathrm{g} / \mathrm{l}$, which was associated with an increase in the intensity of redox processes (Fig. 4).

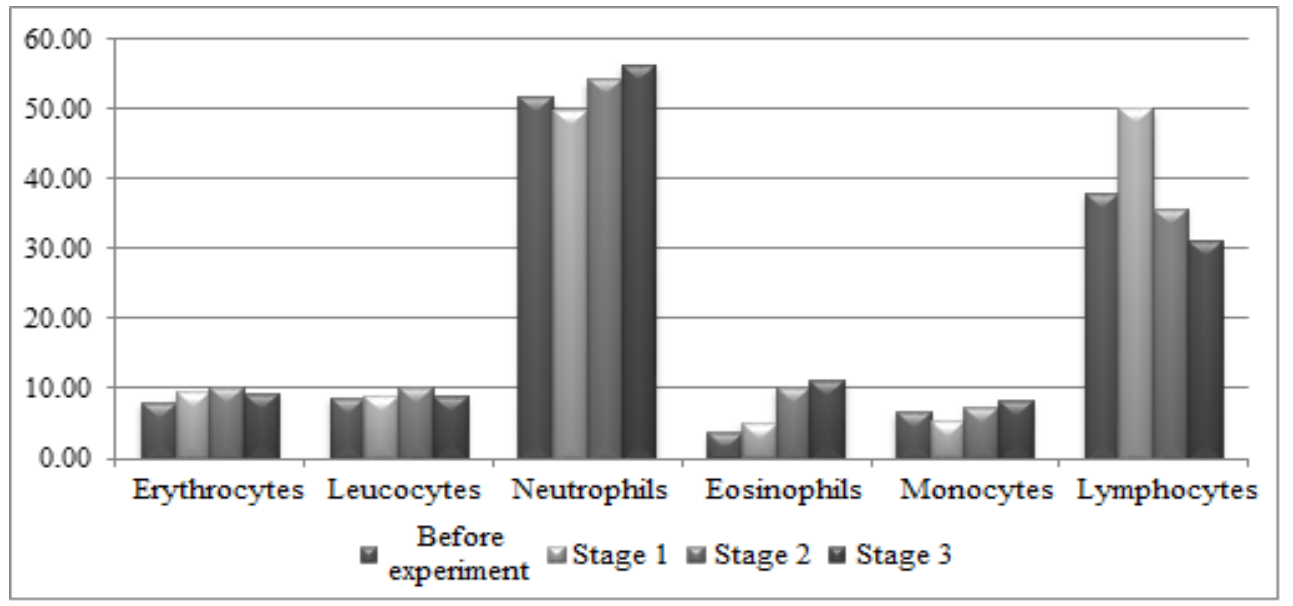

Fig. 4. The content of blood cells of stallions after the use of the preparation

The leukocytes level at the initial stage was $8.67 \times 10^{9} / 1$ and then rose to $10.0 \times 10^{9} / 1$. The level of neutrophils slightly decreased by the first stage of the experiment from 51.66 to $49.67 \%$ and 45 days later it increased to $56.31 \%$, compared with the background. Eosinophils increased from $3.67 \%$ to $10 \%$ in 21 days and to $11 \%$ in 1.5 months after the first use of the nanocomposition.

The functional activity of T-helpers that bind the T- and B-subsystems of immunity rose to $1.77 \times 10^{9} / 1$ at the beginning of the experiment and this indicator remained high throughout the study period. The concentration of T-suppressors was low and amounted to $0.77 \times 10^{9} / 1$ and after the introduction of the preparation it rose to $1.51 \times 10^{9} / 1$, but then decreased to $0.47 \times 10^{9} / 1$ by stage 3 .

Studies have shown that a week after introducing the preparation the level of testosterone increased from $0.34 \mathrm{ng} / \mathrm{ml}$ to $0.64 \mathrm{ng} / \mathrm{ml}$. This was due to the influence of $\mathrm{Zn}$. 
Then the indicator decreased to $0.38 \mathrm{ng} / \mathrm{ml}$ and the repeated use of the preparation contributed to an increase in the concentration of the hormone to $1.08 \mathrm{ng} / \mathrm{ml}$.

\section{Conclusion}

1. Comprehensive physiological studies have established reliable seasonal differences in biochemical blood parameters of stallions.

2. Based on the studies, some features of blood morphology were noted in connection with seasons: an increase in the concentration of erythrocytes, leucocytes, hemoglobin, eosinophils and lymphocytes in spring.

3 The level of testosterone in the blood of stallions had a pronounced seasonal dependence, so there was an increase in spring and summer and a decrease in autumn.

4. When a mating campaign, the content of T-cell subpopulations in animals increased, which indicated the activation of specific and non-specific immunity factors.

5. The positive effect of feeding the preparation of nanosized metals on metabolic and enzymatic processes has been established.

\section{References}

1. E.Yu. Borodkina, Blood parameters of brood and sporting horses in relation to the functional state. Thesis of Cand. of Biol. Science (2008)

2. L.M. Dvinskaya, The influence of the season and dosed work on the change in blood composition in horses of various breeds Dissertation abstract (1976)

3. A.M. Zemskov, V. M. Zemskov and M. A. Zemskov, J. of Microbiology, Epidemiology and Immunobiology, 4, 105-109 (2005)

4. E.A. Karyuk, Immune status, natural microbiocenosis, mineral metabolism and their correction in sporting horses, Dissertation abstract (2004)

5. N.N. Gluschenko, O. A. Bogosovskaya, I. P. Olkhovskaya, Chemical Physics, 4, 79 (2002)

6. A.A. Nazarova, I. A. Stepanova, G. I. Churilov, S. D. Polischuk, V. V. Churilova and D.G. Churilov, Intern. J. of Nanotechnology, 16, 122 (2019)

7. S. Polischuk, IOP Conference Series: Materials Science and Engineering, 98(1) (2015)

8. S. Polischuk, A. Nazarova and I. Stepanova, IOP Conference Series: Materials Science and Engineering, 98(1) (2015) 